\title{
Radiosensitization of esophageal carcinoma cells by knockdown of RNF2 expression
}

\author{
XING-XIAO YANG ${ }^{1}$, MING MA $^{2}$, MEI-XIANG SANG ${ }^{3}$, XUE-XIAO WANG $^{4}$, \\ HENG SONG ${ }^{1}$, ZHI-KUN LIU ${ }^{1}$ and SHU-CHAI ZHU ${ }^{1}$ \\ Departments of ${ }^{1}$ Radiation Oncology, ${ }^{2}$ Clinical Laboratory, ${ }^{3}$ Research Centre, Department of Biotherapy, and \\ ${ }^{4}$ Division of Cancer Biotherapy, The Fourth Hospital of Hebei Medical University, Shijiazhuang, Hebei 050011, P.R. China
}

Received December 4, 2015; Accepted January 26, 2016

DOI: $10.3892 /$ ijo.2016.3404

\begin{abstract}
Radiotherapy has been widely used for the treatment of cancer patients, especially for esophageal cancer patients. Ring finger protein 2 (RNF2) plays an important role in promoting the growth of cancer cells after exposure to irradiation. The present study aims to characterize the proliferative effects of RNF2 on cancer cells, and its mechanisms on the growth of esophageal cancer cells. We demonstrate that expression of RNF2 was markedly upregulated in esophageal cancer cell lines and surgically resected cancer specimens. In addition, RNF2 expression level is positively correlated with the presence of tumor size, lymph node metastases and negatively correlated with patient survival rates, suggesting that it plays an important role in the progression of esophageal cancer. Furthermore, the expression of RNF2 at both mRNA and protein levels in esophageal cancer ECA109 and TE13 cells was detected by real-time PCR and western blot assay after shRNA targeting RNF2. Co-immunoprecipitation (Co-IP) assay and western blot analysis were employed to detect the interaction between RNF2 and r-H2AX, H2AK119ub, and the expression of proteins associated with cell cycle and apoptosis, respectively. We used flow cytometry assay to analyze cell cycle and apoptosis of transfected cells, and further examined cellular growth in vitro and in vivo. shRNA targeting RNF2 gene and protein downregulated RNF2 expression after transfection for $24 \mathrm{~h}$. The proliferation of tumor cells in RNF2-shRNA group was suppressed after radiotherapy. In addition, the interaction of RNF2, H2AK119ub, r-H2AX was increased after exposure to IR, followed by increasing apoptosis rates and inducing the arrest at G0/G1 phase after irradiation and shRNA targeting
\end{abstract}

Correspondence to: Professor Shu-Chai Zhu, Department of Radiation Oncology, The Fourth Hospital of Hebei Medical University, 12 Jiankang Road, Shijiazhuang, Hebei 050011, P.R. China

E-mail: sczhu1965@163.com

Key words: DNA damage response, esophageal cancer, ring finger protein 2 , radiosensitivity
RNF2. Expression of the short-hairpin RNA is also correlated with the upregulation of p16 and Bax, and the downregulation of cyclin D2, cyclin-dependent kinase (CDK)-4, H2AX and $\mathrm{Bcl}-2$. RNF2 gene knockdown induces radiosensitivity of esophageal cancer cells in vitro and significantly inhibits the growth of tumor cells. The mechanisms include inducing the cell cycle arrest at G0/G1 phase and promoting apoptosis.

\section{Introduction}

Esophageal carcinoma is one of alimentary canal malignancies with high incidence of approximately 0.3104 million new malignancies worldwide each year. Despite extensive application in its diagnosis and treatment, recurrence of malignancy remains the main cause of high mortality after treatment for esophageal carcinoma patients. Current treatments, including surgical intervention, radiotherapy and chemotherapy, are moderately effective in the early-stage cases, but are less effective in more advanced cases (1). For example, patients with esophageal carcinoma may benefit from radiotherapy (RT) to a certain degree, however, patient prognosis remains unsatisfactory and unpredictable due to profound radioresistance. Thus, identification of key molecules or pathways specifically expressed in esophageal carcinoma that are essential for the growth of cancer cells may provide novel therapeutic targets and ultimately lead to improved survival. Research over the past years clearly implicates multiple genetic alterations in the development and progression of esophageal carcinoma (2), including those that have important functions in cell growth, metastasis, DNA damage and repair (3).

Ring finger protein (RNF2), a member of the polycomb group of transcriptional repressors, has been detected in a variety of human carcinoma specimens in various stages. In particular, RNF2 is overexpressed in a number of malignancies $(4,5)$. GeneChip analysis also showed that RNF2 can be used to predict cancer metastasis (6), promote cancer cell proliferation and invasion, resist apoptosis and enhance transfer capabilities (7). Moreover, as an active heterodimer E3 ligase, RNF2 may be associated with the ubiquitination and phosphorylation of $\mathrm{H} 2 \mathrm{AX}$, which is thought to be a critical sensor that can initiate DNA damage response (DDR) $(8,9)$. It has been also shown that $\mathrm{H} 2 \mathrm{AX}$ was associated with radiosensitization of esophageal cancer cells (10). However, how the 
function of RNF2 in radiosensitivity is regulated remains a fundamental question that needs to be answered to elucidate the essential mechanisms controlling DDR.

To identify new and crucial factors regulating the function of RNF2 in DDR, we conducted a proteomic analysis to systematically identify RNF2 interacting proteins. To the best of our knowledge, the mechanisms by which RNF2 promoted the growth of esophageal carcinoma cells after radiotherapy has not been reported thus far. Given the important role of RNF2 in ionizing radiation-induced DDR, we hypothesize that silencing of RNF2 may bring in DNA damage pathway defects and thus increase the radiosensitivity. In the present study, we attempted verification of this hypothesis through different cells lines in vitro and explored the mechanisms through which RNF2 induces oncogenesis and tumor progression.

\section{Materials and methods}

Tissue specimens and immunohistochemical analysis. Sixtyfour esophageal carcinoma tissues and five normal esophageal tissues were obtained from the Department of Thoracic Surgery, Hebei Hospital of the Fourth affiliated Medical University (Hebei, China), from January 2008 to December 2009. Patient consent was obtained for the collection of specimens, and all study protocols were approved by the Ethics Committee for Clinical Research of the Fourth affiliated Medical University. Immunohistochemistry protocols were performed as previously described (11). In brief, slides were incubated with an anti-RNF2 monoclonal antibody (1:100, EPR12245; Upstate, Lake Placid, NY, USA) followed by incubation with a horseradish peroxidase-conjugated antimouse secondary antibody (1:200; Dako, Glostrup, Denmark). Antibody binding was visualized using 3,3'-diaminobenzidine and counterstained with hematoxylin. Negative control sections were incubated with PBS instead of the primary antibody. Immunostained results were independently evaluated by two pathologists who were blinded to the clinical and histopathological features. Ring finger protein 2 (RNF2) cytoplasm accumulation was quantified as a percentage of the total number of cytoplasm detected in at least 4-5 random high power fields (x400) in each section. Cases with $>10 \%$ of cells staining for RNF2 were scored as positive samples (12).

Cell lines and cell culture. Five human esophageal cancer cell lines, TE13, TE1, KYSE30, EC9706 and ECA109, and the normal esophageal cell line HEEC, were maintained at $37^{\circ} \mathrm{C}$ and $5 \% \mathrm{CO}_{2}$ in RPMI-1640 medium (Gibco, Gaithersburg, MD, USA) supplemented with $10 \%$ fetal bovine serum (FBS; Invitrogen, Carlsbad, CA, USA), penicillin (100 U/ml), and streptomycin $(0.1 \mathrm{mg} / \mathrm{ml})$.

$X$-ray irradiation. Irradiation was performed at room temperature with a 6MV Siemens linear accelerator (Siemens, Concord, CA, USA) at a dose rate of $2 \mathrm{~Gy} / \mathrm{min}$. After irradiation, cells were recovered in an incubator for the indicated time until harvesting.

shRNA transfection. For the shRNA analyses, human RNF2 small interfering RNA (shRNA) with the nucleotide sequence
5'-GGUAACGCCACUGUUGAUCACUUAU-3' (sense) and 5'-AUAAGUGAUCAACAGUGGCGUUACC-3' (antisense), corresponding to part of the RNF2 mRNA, and the negative control scrambled shRNA (NC-shRNA: sense, 5'-UUCUCC GAACGUGUCACGUTT-3' and antisense, 5'-ACGUGACAG GUUCGGAGAATT-3') were designed and purchased from Invitrogen. All of the shRNA sequences were subjected to basic local alignment search tool (BLAST) to confirm the absence of homology to any additional known coding sequences in the human genome. Cells were transfected using Lipofectamine RNAiMAX (Invitrogen) according to the manufacturer's protocol. Briefly, one day prior the transfection, ECA109 and TE13 cells (5x10\% /well) were cultured in 6 -well tissue culture plates until they reached $50 \%$ confluence, then the cells were transiently transfected with either RNF2shRNA (Shanghai Genechem Co., Ltd., Shanghai, China) or NC-shRNA (100 nM). Cells were collected $24 \mathrm{~h}$ after transduction with shRNA and were selected in puromycin for stable clones. Subsequently, the cells were used for irradiation as indicated.

Quantitative real-time reverse transcription-polymerase chain reaction ( $q R T-P C R)$. Total RNAs were extracted by using TRIzol reagent. Real-time PCR was then performed using Platinum SYBR-Green qPCR SuperMix-UDG (Invitrogen) according to the manufacturer's protocol. Briefly, after the reverse transcription reaction at $42^{\circ} \mathrm{C}$ for $60 \mathrm{~min}$ and $70^{\circ} \mathrm{C}$ for $5 \mathrm{~min}$, cDNAs was synthesized using the ReverAid First Strand cDNA Synthesis kit (Thermo Fisher Scientific, Waltham, MA USA), then initially denatured at $94^{\circ} \mathrm{C}$ for $30 \mathrm{sec}$, and followed by 40 cycles of repeated procedure as follows: denatured at $94^{\circ} \mathrm{C}$ for $5 \mathrm{sec}$, annealed at $56^{\circ} \mathrm{C}$ for $15 \mathrm{sec}$ and extended at $72^{\circ} \mathrm{C}$ for $10 \mathrm{sec}$. As a control, the levels of glyceraldehyde phosphate dehydrogenase (GAPDH) expression were also analyzed. Incorporation of the SYBR-Green dye into PCR products was monitored in real-time with LightCycler real-time PCR detection system (Roche Applied Science, Indianapolis, IN, USA), thereby allowing determination of the threshold cycle $(\mathrm{Ct})$ at which exponential amplification of products begins. Independent experiments were repeated three times for each sample and the relative expression levels of genes were analyzed by using $2^{-\Delta \Delta C t}$ method (13).

Western blot analysis. The cellular total protein was solubilized in RIPA lysis buffer (1\% Triton X-100, $150 \mathrm{mM} \mathrm{NaCl}$, 10 mM Tris-HCl, pH 7.4, 1 mM EDTA, 1 Mm EGTA, pH 8.0, $0.2 \mathrm{mM} \mathrm{Na}_{3} \mathrm{VO}_{4}, 0.2 \mathrm{mM}$ phenylmethylsulfonylfluride and $0.5 \% \mathrm{NP}-40)$. The protein amount was evaluated by using BCA assays (Pierce, Rockford, IL, USA) and separated on $10 \%$ SDS-PAGE gel, and electrotransferred to a PVDF membrane (Pierce). The membrane was incubated overnight at $4^{\circ} \mathrm{C}$ with the indicated antibodies. The specific antibodies were rabbit RNF2 antibody (1:10,000; Abcam, Cambridge, USA), anti-rH2AX (1:10,000; Abcam), anti-H2AK119ub (1:10,00; Millipore, Billerica, MA, USA), rabbit Bcl-2 (1:1,000; Abcam), and anti-Bax (1:500; Abcam), anti-H2AX (1:1,000; Abcam), anti-p16 (1:50,00; Abcam), anti-cyclin D2 (1:500; Abcam), anti-CDK4 (1:1,000; Abcam) and rabbit $\beta$-actin (1:10,000; Bioworld Technology, Inc., Louis Park, MN, USA). After washing for $3 \times 5 \mathrm{~min}$ with TBS-T, the membrane was incubated 
with secondary anti-rabbit $\mathrm{IgG}$ for $1 \mathrm{~h}$ at room temperature away from light. The membrane was scanned for the relative value of protein expression in gray scale by Image-Pro plus software 6.0 (Media Cybernetics, Sliver Spring, MD, USA). The levels of the proteins were calculated as the ratio of the intensity of protein to that of $\beta$-actin. Experiments were carried out in triplicate wells each time and repeated three times.

Cell proliferation assay. The cells ( $2 \times 10^{3} /$ well) were cultured in 96-well tissue culture plates until they reached $50 \%$ confluence, then transfected with a final concentration of $100 \mathrm{nM}$. After the cells had been transfected for $24 \mathrm{~h}$, viability of the cells were determined at 24, 48, 72 and $96 \mathrm{~h}$ after irradiation using the Cell Titer $96 \mathrm{AQ}_{\text {ueous }}$ One Solution cell proliferation assay (MTS) that was purchased from the Dojindo Molecular Technologies (Gaithersburg, MD, USA). Briefly, cells were collected and incubated in medium containing $5 \mathrm{mg} / \mathrm{ml}$ MTS reagent (Promega, Madison, WI, USA) at $37^{\circ} \mathrm{C}$ for $2 \mathrm{~h}$. The absorbance at $492 \mathrm{~nm}$ was measured by an enzyme linked immunosorbent assay (ELISA) plate reader. This experiment was repeated three times.

Co-immunoprecipitation (Co-IP) assay. Cell lysates were first pre-cleared with $25 \mathrm{ml}$ of Protein A-agarose (Santa Cruz Biotechnology). The supernatants were immunoprecipitated with $2 \mathrm{mg}$ of anti-rH2AX (1:100; Abcam), anti-H2AK119ub (1:100; Millipore), anti-RNF2 (1:100; Abcam) antibody for $2 \mathrm{~h}$ at $4^{\circ} \mathrm{C}$, followed by incubation with protein A-agarose overnight at $4^{\circ} \mathrm{C}$. Protein A-agarose-antigen antibody complexes were pelleted by centrifugation at $12,000 \mathrm{x} \mathrm{g}$ for $60 \mathrm{sec}$ at $4^{\circ} \mathrm{C}$. The pellets were washed five times with $1 \mathrm{ml} \mathrm{IPH}$ buffer, for $20 \mathrm{~min}$ each time at $4^{\circ} \mathrm{C}$. Bound proteins were resolved by SDS-PAGE, followed by western blot analysis with antibodies against rH2AX, H2AK119ub and RNF2.

Analysis of cell cycle and apoptosis. Both cell cycle distribution and spontaneous apoptosis events were detected by using a FACSCalibur II sorter and CellQuest FACS system (BD Biosciences, San Jose, CA, USA). To analyze cell cycle distribution, cells were transfected by using shRNA for $24 \mathrm{~h}$ and stimulated with irradiation for $24 \mathrm{~h}$ before being harvested. Cells were fixed with $70 \%$ ethanol at $4^{\circ} \mathrm{C}$ overnight, washed twice with PBS, and resuspended in staining solution $(50 \mu \mathrm{g} / \mathrm{ml}$ propidium iodide, $1 \mathrm{mg} / \mathrm{ml}$ RNase A, $0.1 \%$ Triton $\mathrm{X}-100$ in PBS) for $30 \mathrm{~min}$ at $37^{\circ} \mathrm{C}$ in the dark. To detect the extent of apoptosis under stress conditions, cells were transfected using shRNA for $24 \mathrm{~h}$ before irradiated and stained with fluorescein isothiocyanate (FITC)-conjugated Annexin V and 7-aminoactinomycin D (7-AAD) using the Annexin V-FITC apoptosis detection kit (BD Biosciences) according to the manufacturer's protocol.

Colony formation assay. Cell survival curves were generated by a standard colony formation assay with minor modifications (14). Precooled tumor cells were irradiated by graded single doses (0-8 Gy) in control, NC and RNF2 shRNA groups, seeded in Petri dishes, and then cultivated in RPMI-1640 supplemented with $10 \%$ FBS. The experiments were repeated at least twice. Two weeks later, the cells were fixed and stained with crystal violet $(0.6 \%)$. Colonies of exceeding 50 cells were scored as survivors.

Statistical analysis. Statistical analysis was conducted with the SPSS software package (version 13.0). All data were presented as the mean \pm standard deviation (SD), and analyzed using ANOVA with the SPSS 13.0. For all tests, a P-value $<0.05$ and 0.01 was considered to be statistically significant and indicated by asterisks in the figures. All P-values given were the results of two-sided tests. Data were obtained from at least three independent experiments with a similar pattern.

\section{Results}

RNF2 expression is increased in esophageal cancer cells and specimens. The expression of RNF2 in esophageal cancer and normal esophageal tissues was analyzed by immunohistochemistry. In contrast to previous reports (15), RNF2 was mainly expressed in neoplastic epithelial cytoplasm, plasmalemma and occasionally in the cell nuclei (Fig. 1A-b and -c). In addition, no staining or only weak staining was seen in normal epithelium cells (Fig. 1A-a). For the 64 esophageal cancer patients, increased cytoplasm accumulation of RNF2 was found in $35(54.69 \%)$ specimens. Furthermore, we detected RNF2 expression in five esophageal cancer cell lines (TE13, TE1, KYSE30, EC9706 and ECA109) and the immortal esophageal epithelial cell line HEEC. The levels of RNF2 expression in the esophageal cell lines were higher than that for the HEEC cell line (Fig. 1A-f).

RNF2 overexpression is associated with the progression and adverse prognosis of esophageal cancer. To investigate the clinical role of RNF2 during esophageal cancer development, we analyzed the correlation between RNF2 expression and the clinicopathological features of patients with esophageal cancer. As shown in Table I, the cytoplasm accumulation of RNF2 in esophageal cancer was significantly associated with tumor size, clinical stage and lymph node metastases $(\mathrm{P}<0.05)$, indicating a correlation between RNF2 expression and esophageal cancer invasion, and metastasis. However, no evident correlation were observed between the expression of RNF2 and other clinical features such as patient age, gender and histological grade ( $\mathrm{P}>0.05$ for all comparisons). Furthermore, Kaplan-Meier survival analysis demonstrated that patients harboring RNF2 overexpression had a significantly shorter overall survival than patients with lower levels of RNF2 expression $(\mathrm{P}<0.001$, log-rank test; Fig. 1A-e). Taken together, these observations indicate that RNF2 could contribute to the evaluation of the prognosis in patients with esophageal cancer.

Specific knockdown of RNF2 expression by shRNA inhibits the growth and improves the radiosensitivity of esophageal cancer cells after IR in vitro and in vivo. To address the functional importance of the RNF2 gene, we first employed RNF2-specific shRNA to deplete its expressions in ECA109 and TE13 cells, both of which were treated with negative control (NC) shRNA or shRNA targeting the RNF2 gene owing to their high levels of RNF2. After transfected for $24 \mathrm{~h}$, the expression of RNF2 in cells was subsequently determined by real-time quantitative reverse transcription-polymerase 
A
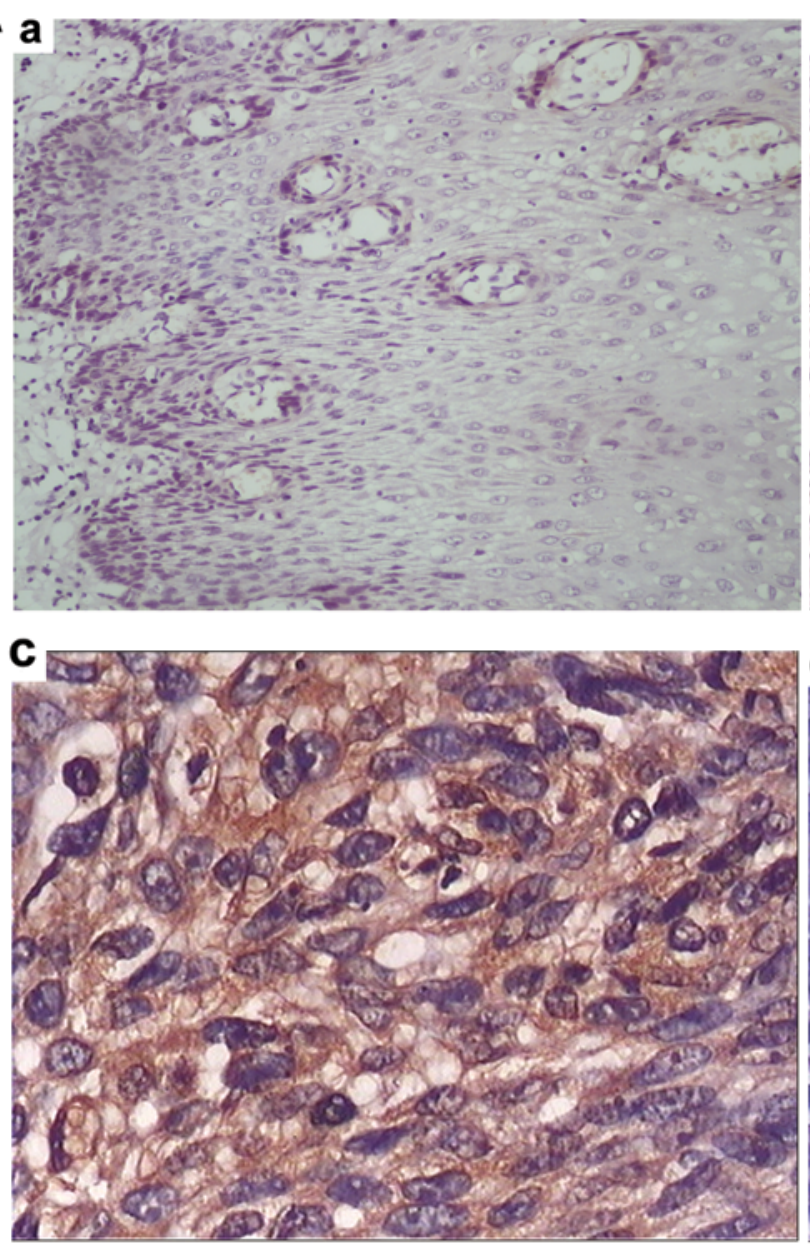
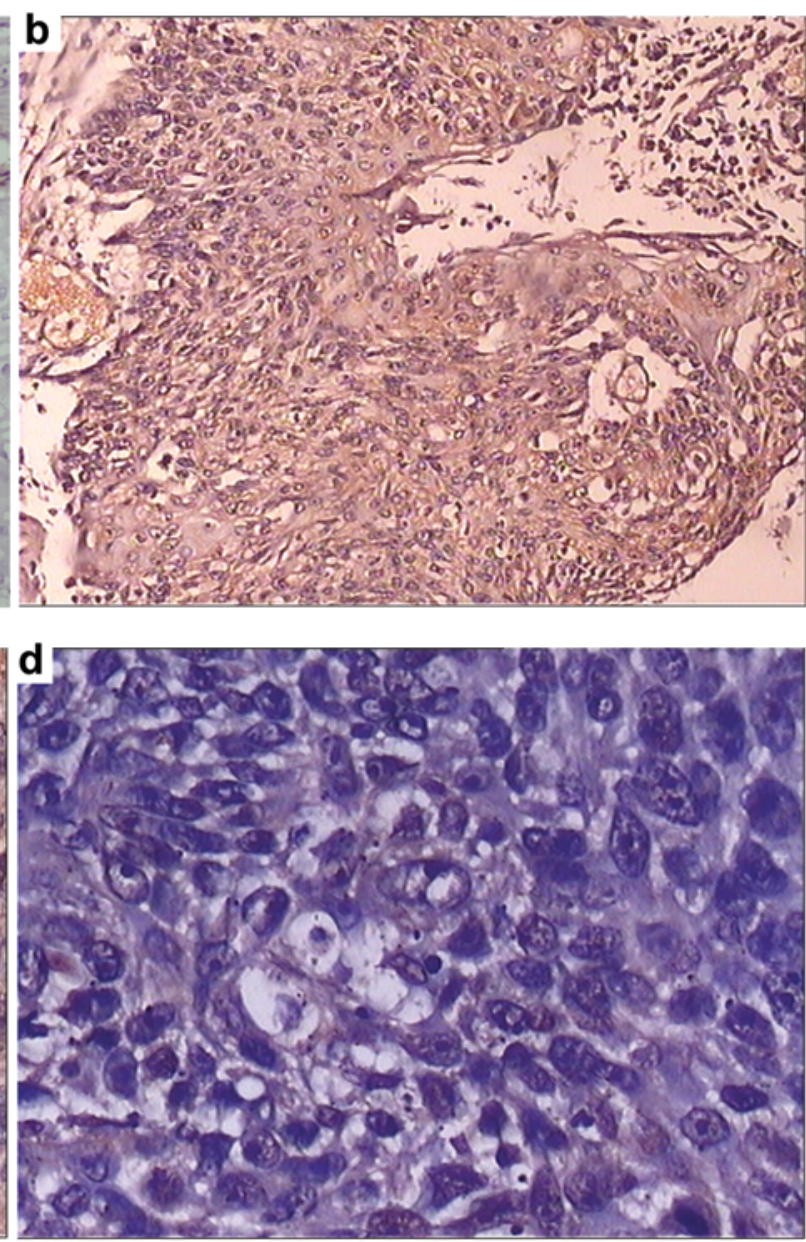
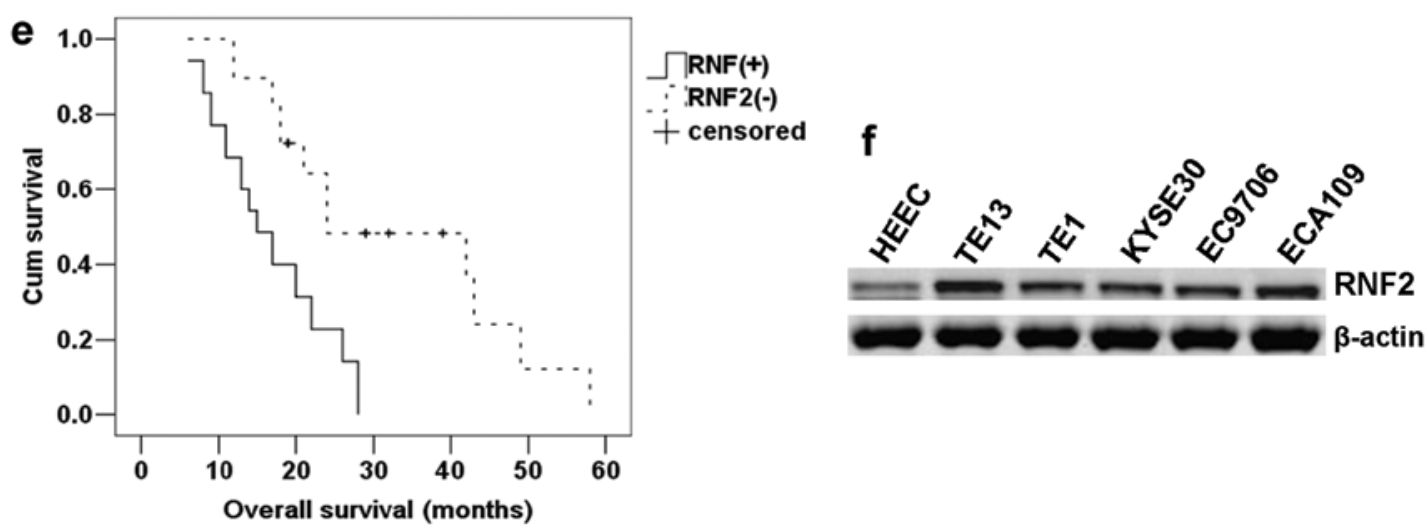

Figure 1. Expression of Ring finger protein 2 (RNF2) in human esophageal clinical specimens and cell lines. (A-a-d) Immunohistochemical analysis of RNF2 expression in normal adult esophagus (a) and esophageal carcinoma tissues (b-d). Ring finger protein 2 (RNF2) staining is mainly localized in the cytoplasm and plasmalemma of cancerous cells and seldom in the nuclei. (a) Weak or absent RNF2 in a normal esophagus epithelium. (b and c) Strong RNF2 staining in esophageal carcinoma. (d) Ring finger protein 2 (RNF2)-negative staining in esophageal carcinoma. Magnification: (a) x200; (c and d) x400; (b) x100. (A-e) Kaplan-Meier overall survival curves for 64 patients with esophageal carcinoma. Ring finger protein 2 (RNF2) overexpression was associated with a significantly shorter overall survival ( $\mathrm{P}<0.01$, log-rank test). (A-f) Western blot analysis of RNF2 expression in five esophageal cancer cell lines and the normal human esophageal epithelial cell line HEEC. $\beta$-actin was used as a loading control.

chain reaction (qRT-PCR) and western blot analysis. The qRT-PCR analysis confirmed that the levels of glyceraldehyde3-phosphate dehydrogenase (GAPDH) were unaffected by transfection of RNF2 shRNA or NC shRNA. As shown in Fig. 1B, qRT-PCR showed that the shRNA RNF2 effectively suppressed the expression of RNF2 in both ECA109 and TE13 cells $(\mathrm{P}<0.01)$. Furthermore, the empty vector had no effect on the expression of RNF2 in either cell line. Similar results were observed in the western blot analysis (Fig. 1C). Therefore, ECA109-RNF2 shRNA and TE13-RNF2 shRNA cells were further characterized.

To evaluate the effect of RNF2 depletion on cell proliferation, cell viability was first examined by using MTS assay. As shown in Fig. 2A, the proliferation rate between ECA109 and TE13 cells was not significantly different in three groups at each time point without irradiation. In contrast, RNF2 deple- 
B
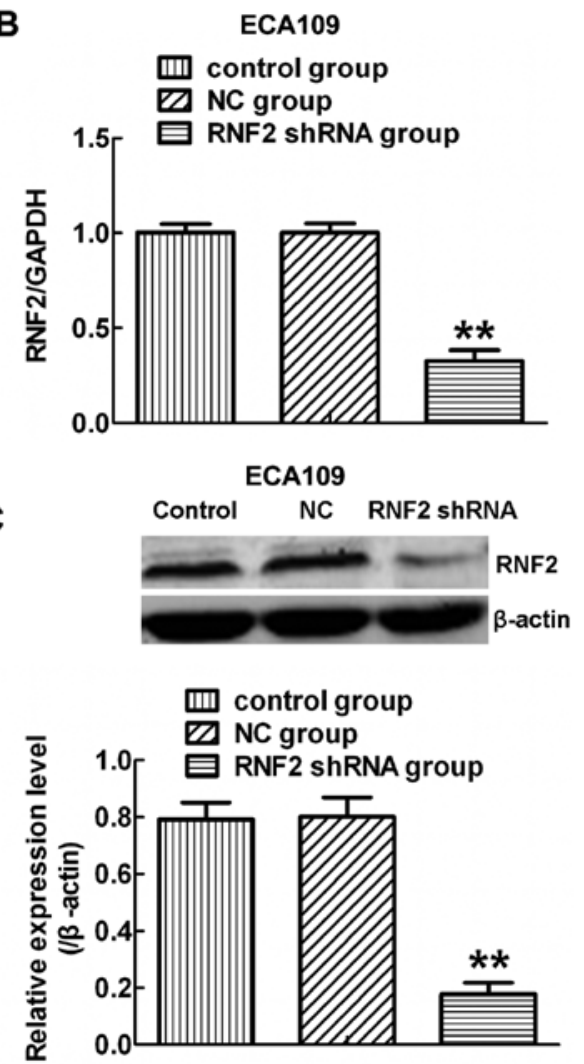

TE13
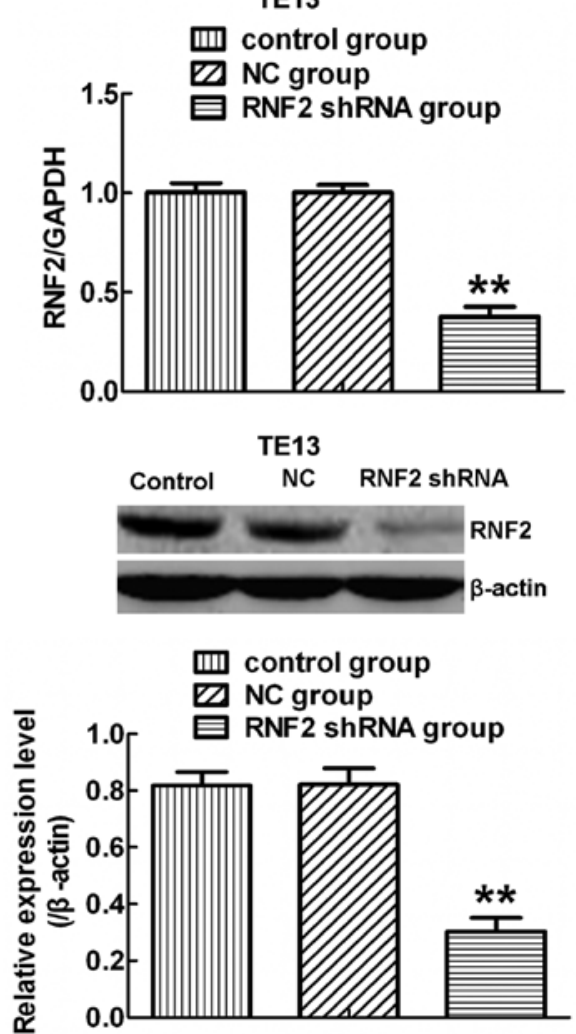

Figure 1. Continued. (B) qRT-PCR analysis showed that the mRNA expression levels of RNF2 in ECA109 cells and TE13 cells were significantly downregulated by shRNA targeting RNF2. (C) Similar results were obtained in western blot analysis. ** $\mathrm{P}<0.01$ compared with control group and NC group.

Table I. Association between RNF2 expression and clinicopathological variables of patients with esophageal cancer.

\begin{tabular}{lccc}
\hline & \multicolumn{2}{c}{ RNF2 expression } & \\
\cline { 2 - 3 } Variables & Positive & Negative & P-value \\
\hline Age (years) & & & \\
$>60$ & 19 & 13 & 0.451 \\
$\leq 60$ & 16 & 16 & \\
Gender & & & \\
$\quad$ Male & 18 & 14 & 0.802 \\
Female & 17 & 15 & \\
Tumor size (cm) & & & \\
$\leq 2$ & 13 & 19 & 0.024 \\
$>2$ & 22 & 10 & \\
Histological grade & & & \\
$\quad$ Well or moderated & 16 & 17 & 0.304 \\
$\quad$ Poorly & 19 & 12 & \\
TNM stage & & & \\
I-II & 12 & 18 & 0.027 \\
$\quad$ III-IV & 23 & 11 & \\
Lymph node metastasis & & & \\
$\quad$ Positive & 25 & 12 & 0.015 \\
$\quad$ Negative & 10 & 17 & \\
\hline
\end{tabular}

tion significantly inhibited the growth of ECA109 and TE13 cells compared with cells in control group and $\mathrm{NC}$ group after IR ( $\mathrm{P}<0.05)$ (Fig. 2B). Moreover, the proliferation level in each group was obviously higher at 48,72 and $96 \mathrm{~h}$ after IR than corresponding unirradiated groups. In addition, we also further detected the radiatiosensitivity in different groups after exposure to IR and found that there was no significant difference between control and NC groups. However, cells in the RNF2 shRNA group had higher sensitivity than the other groups (Fig. 2C). To confirm these findings in vivo, xenograft tumor growth assays were performed in nude mice. Compared with the control cells, injection of ECA109 and TE13 RNF2 shRNA cells led to markedly decreased tumor weight $(\mathrm{P}<0.05$; Fig. 2D). Collectively, these data suggested that the knockdown of RNF2 after irradiation significantly inhibited cells proliferation and tumorigenicity and increased radiosensitivity.

RNF2 interacts with the ubiquitination and phosphorylation of H2AX in ECA109 and TE13 cells in a DNA damageinduced manner. In our experiment, ionizing radiation induced the expression of RNF2, H2AK119ub, r-H2AX in a dose-dependent manner. Moreover, the expression of three kinds of proteins were consistent in ECA109 and TE13 cells (Fig. 3A and B). All were highest at 1 and $2 \mathrm{~h}$, and their expression gradually reduced after this time. By $24 \mathrm{~h}$, levels were restored to unirradiated levels. These data led us to believe that there was some relationship between RNF2 and H2AK119ub, $\mathrm{r}-\mathrm{H} 2 \mathrm{AX}$. Therefore, the specificity of this interaction was 
A

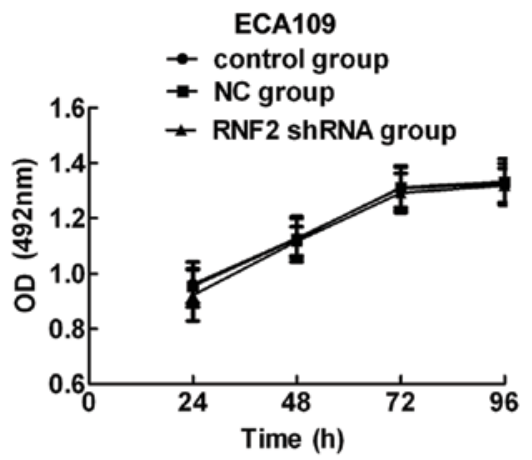

B

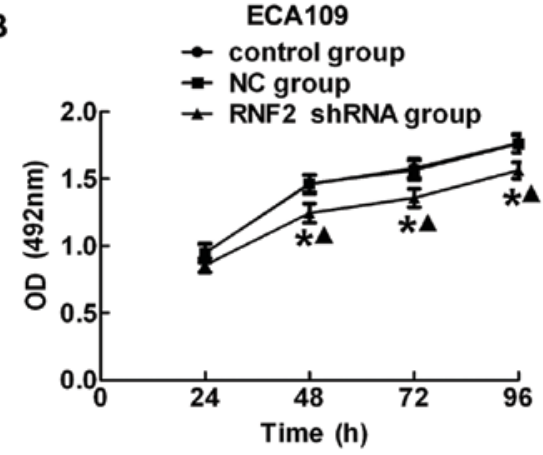

C

ECA109

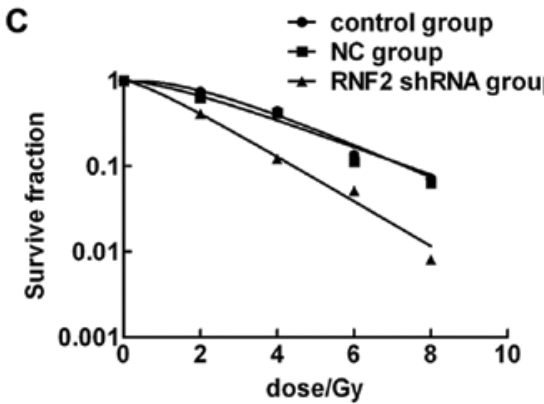

D
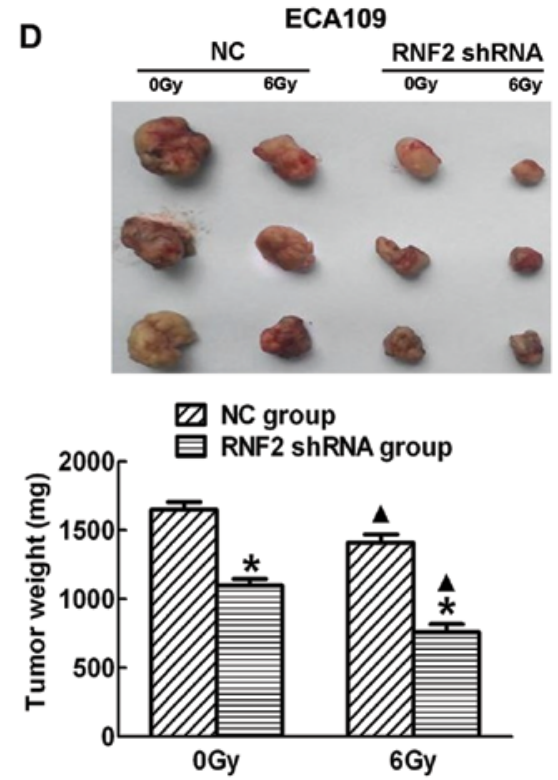

TE13

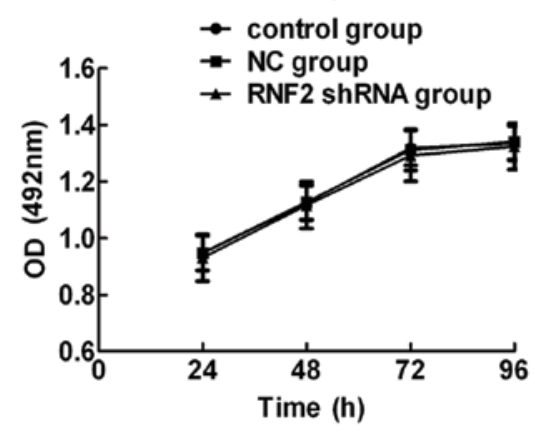

TE13

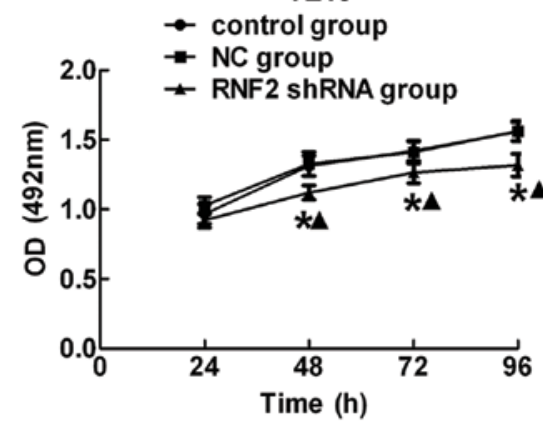

TE13

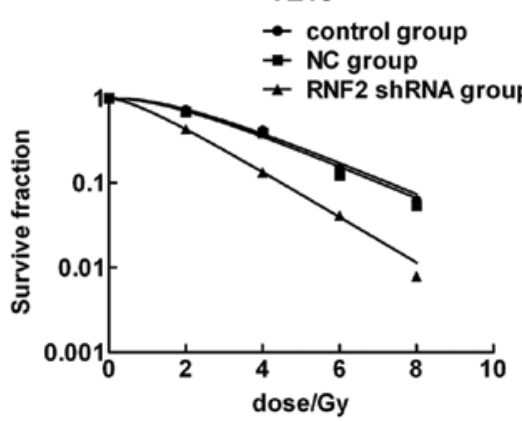

TE13
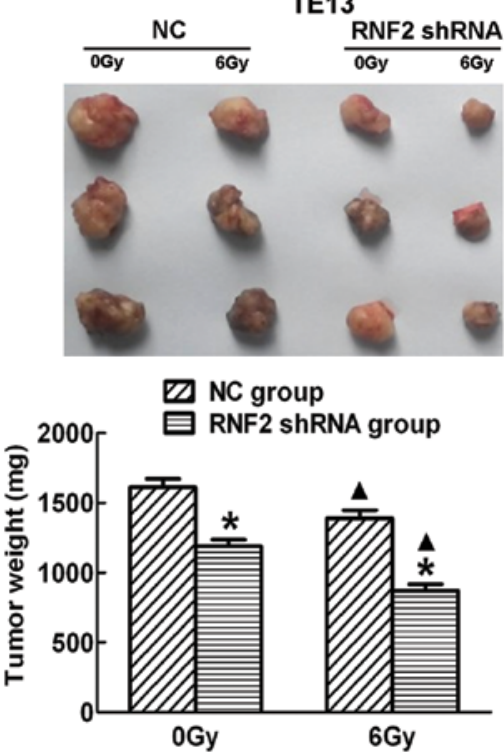

Figure 2. RNF2 depletion causes inhibition of growth and tumorigenesis of esophageal carcinoma cells. There were no obvious difference among control group, NC group and RNF2 shRNA group without irradiation both in ECA109 and TE13 cells (A), while downregulation of RNF2 expression by RNF2 shRNA significantly inhibited the growth of ECA109 and TE13 cells after irradiation (B). Besides, the proliferation levels in the three groups at 48,72 and $96 \mathrm{~h}$ after IR were higher than before irradiation. Survival curves of treated with IR were drawed, respectively. GraphPad Prism 5.0 was used to fit cell survival curves, as well as the radiation biological parameters. Control and NC group cells had a broader shoulder compared to RNF2 shRNA group cells, indicating that they were more radioresistant than the latter $(\mathrm{C})$. The nude mice were sacrificed, the tumors were dissected, and tumor weights were measured, the data are shown as the means \pm standard error for each group $(\mathrm{n}=5)(\mathrm{D}) .{ }^{*} \mathrm{P}<0.05$ compared with control group or $\mathrm{NC}$ group. ${ }^{\wedge} \mathrm{P}<0.05$ compared with corresponding unirradiated group. 

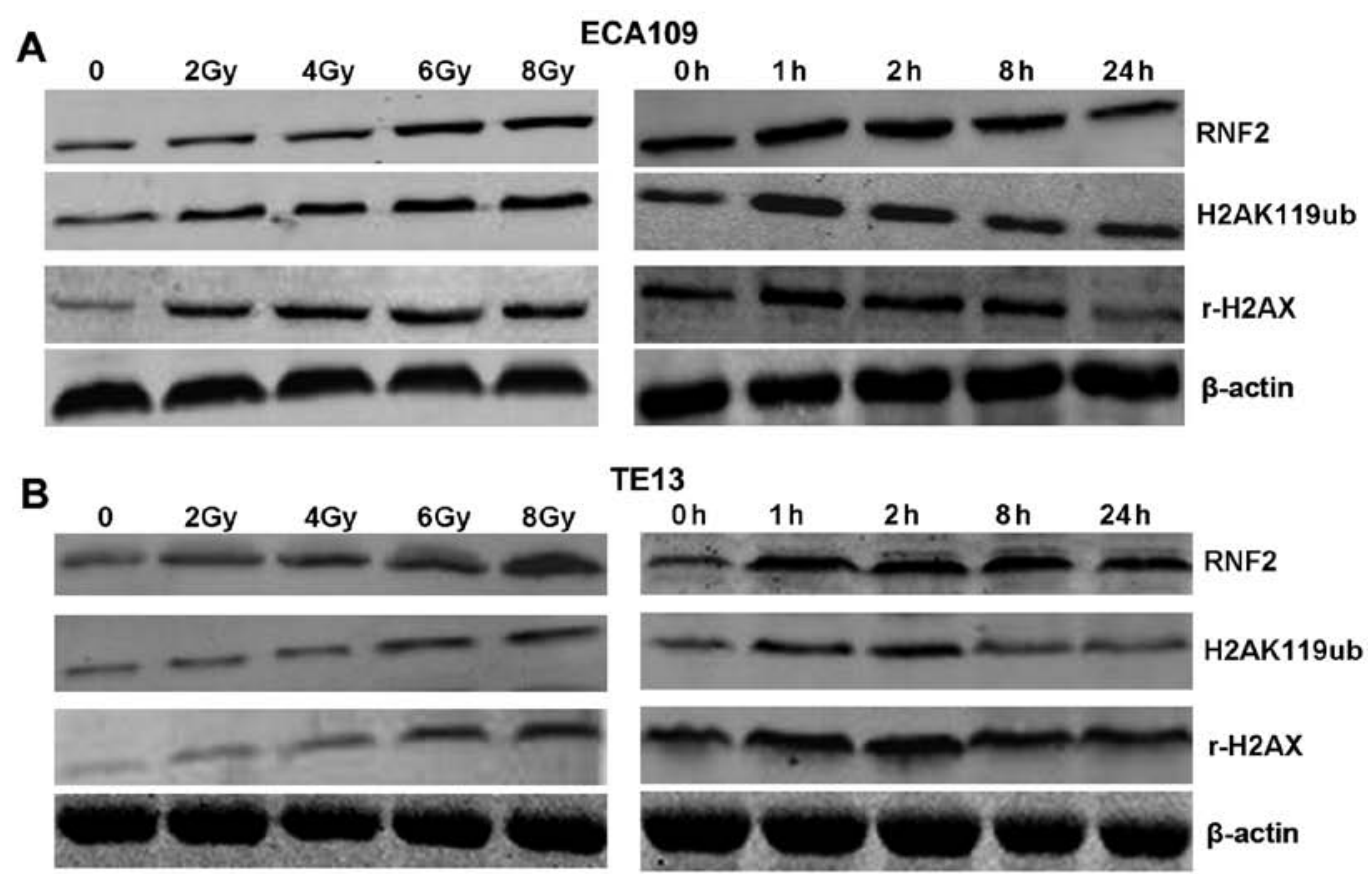

TE13
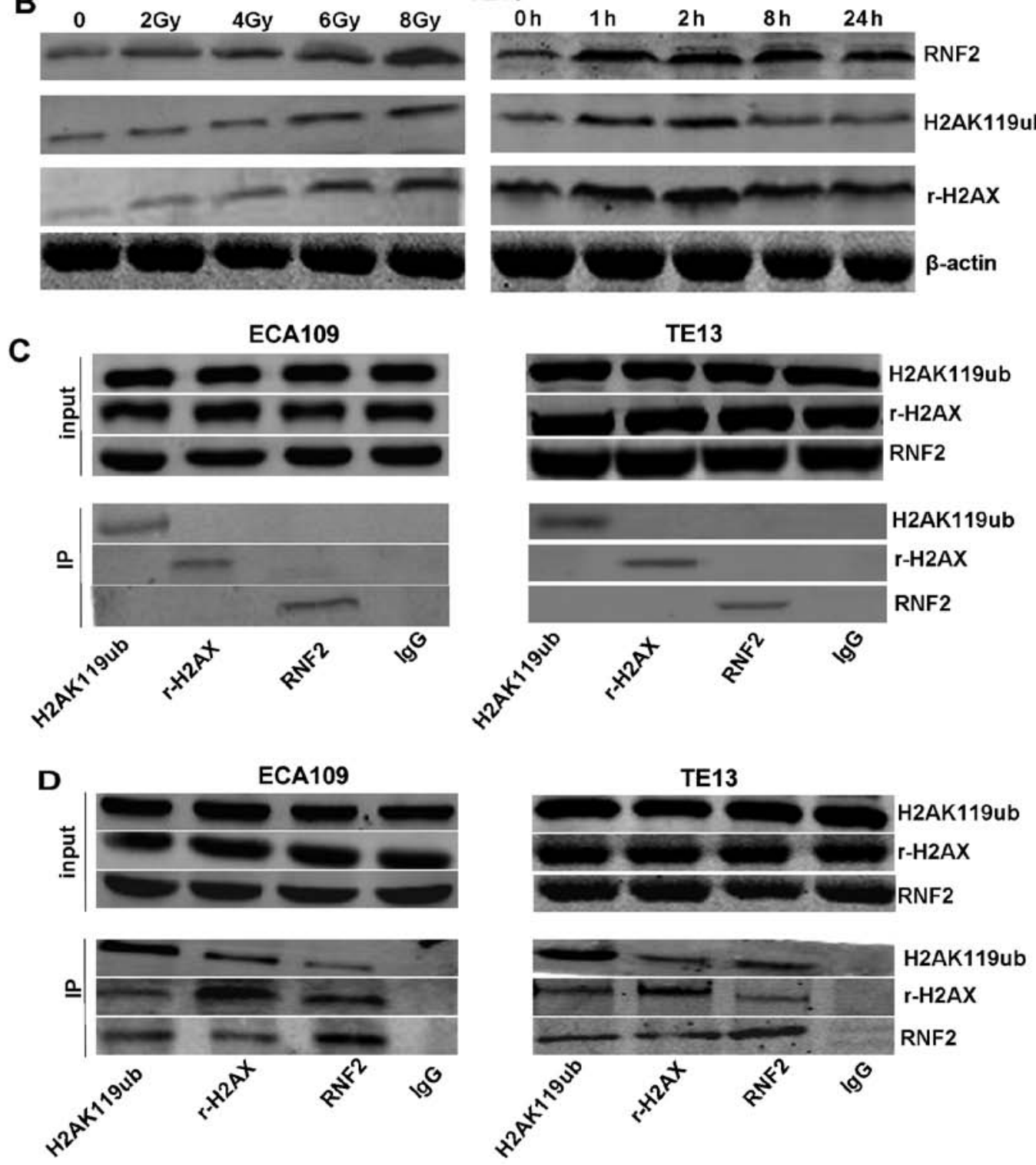

Figure 3. The interaction of RNF2 and H2AK119ub, r-H2AX in ECA109 and TE13 esophageal cancer cells after irradiation or not. The expression of RNF2, r-H2AX and H2AK119ub were observed in ECA109 (A) and TE13 (B) cells by western blotting. Cells were irradiated with 2, 4, 6 or 8 Gy, and fixed for 1 h after IR, followed by being irradiated with $6 \mathrm{~Gy}$ at different times. In addition, there was no significant interaction without irradiation in cells (C), while the interaction between RNF2 and H2AK119ub, r-H2AX was obviously enhanced in cells after irradiation (D), implying that RNF2 may be related to the phosphorylation and ubiquitination of $\mathrm{H} 2 \mathrm{AX}$.

confirmed by co-immunoprecipitation of H2AK119ub, r-H2AX and RNF2. Notably, there was no significant interaction without irradiation (Fig. 3C), while their interaction was obviously enhanced in both ECA109 and TE13 cells upon IR (Fig. 3D), indicating that RNF2 may play an important role in DNA damage repair through inducing the ubiquitination or phosphorylation of H2AX.

Mechanisms of radiosensitization by silencing of RNF2. In order to further explore the mechanisms by silencing of 
A

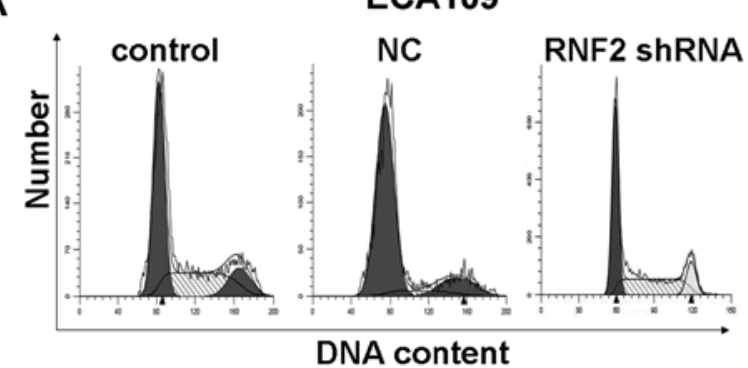

B

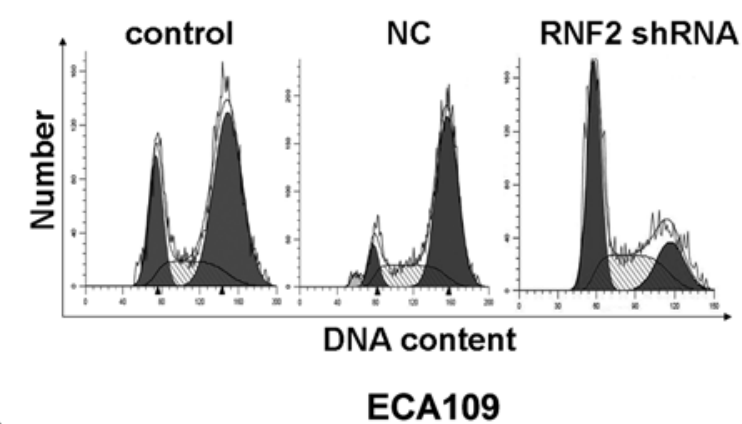

C

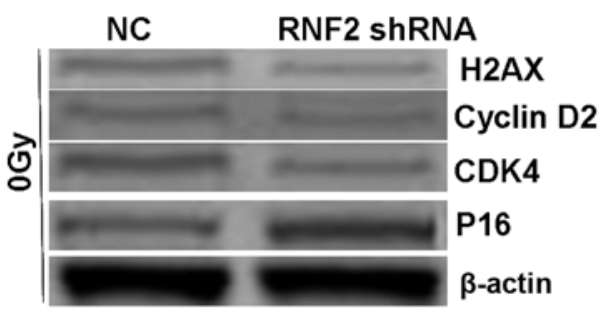

D

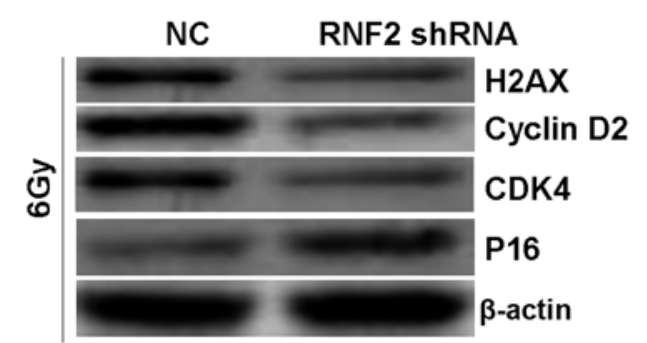

TE13

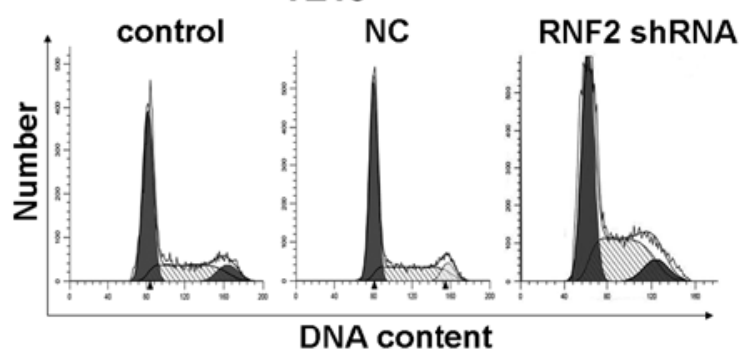

TE13

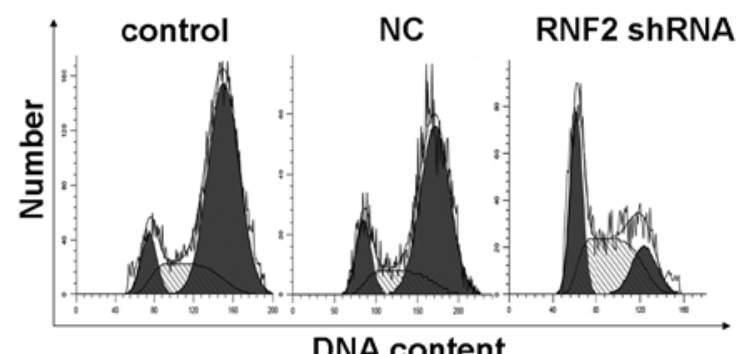

TE13

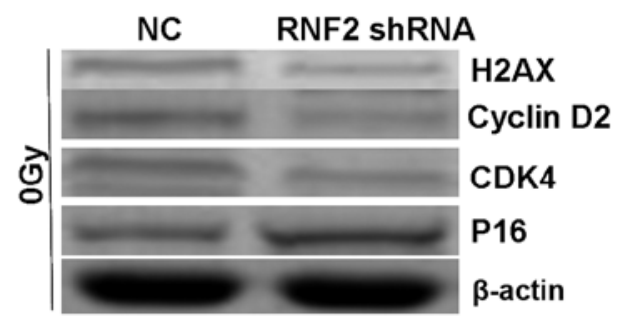

TE13

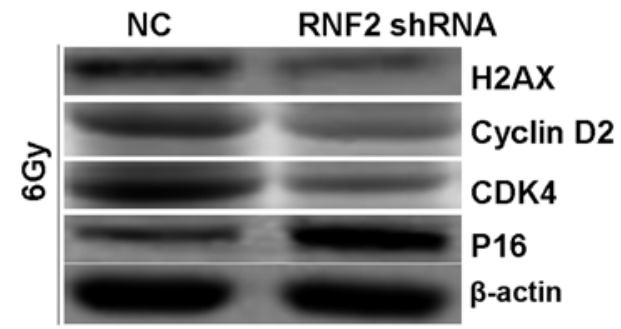

Figure 4. shRNA-RNF2 induces cell cycle arrest at G0/G1 in ECA109 and TE13 cells after IR. ECA109 cells and TE13 cells were pretreated with shRNA for $24 \mathrm{~h}$ and then irradiated with $6 \mathrm{~Gy}$. At $24 \mathrm{~h}$ after IR, the cell cycle distribution was analyzed through FACS with 7-AAD. The changes of cell cycle before IR in control, NC and RNF2 shRNA groups of ECA109 and TE13 cells were no significant differences (A). However, the rates of cell cycle arrest at G2/M phase were significantly higher after exposure to irradiation than that before IR. In addition, the cell cycle arrest at G2/M stage was obviously weakened by silencing the expression of RNF2 after irradiation, while the rate of G0/G1 was increased (B). Furthermore, the expression of several cell cycle-related regulatory factors in ECA109 and TE13 cells after infected with RNF2 shRNA or control was detected before (C) and after (D) IR by western blot assay. $\beta$-actin was used as the loading control. CDK, cyclin-dependent kinase.

RNF2 in promoting radiosensitization of esophageal cancer cells, flow cytometry was performed demonstrating that irradiation could obviously induce cell cycle arrest at G2/M phase after irradiation for $24 \mathrm{~h}$ in both ECA109 and TE13 cells in vitro (Fig. 4B). However, silencing RNF2 by shRNA could cause G1 arrest in cells and reduce compensatorily G2/M phase, which allowed much time to kill more tumor cells, and induced radiosensitivity. If no irradiation, there was no significant difference among RNF2 shRNA group, control group and NC group (Fig. 4A). Our results showed that RNF2 gene knockdown suppressed the entry of cells from G1 into $\mathrm{S}$ phase, inhibited cell growth, and therefore enhanced radiosensitivity. Furthermore, western blotting was performed to explore the cell cycle regulatory role of RNF2. Interestingly, the levels of these indexes were also detected but were not obviously altered before IR (Fig. 4C). However, after RNF2 knockdown, the expression of cyclin D2, cyclin dependent kinase 4 (CDK4) and $\mathrm{H} 2 \mathrm{AX}$ was significantly decreased, while the level of p16 was obviously increased after IR (Fig. 4D). Collectively, these data demonstrated that RNF2 may regulate proteins associated with cell cycle through interaction with $\mathrm{H} 2 \mathrm{AX}$. 
A
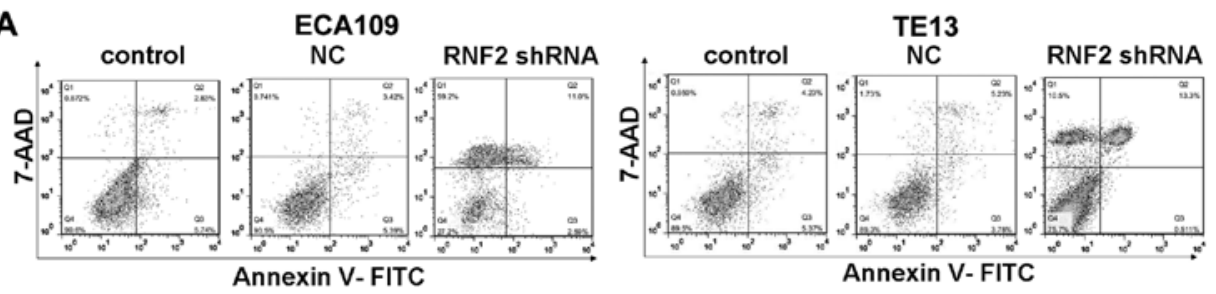

B

ECA109
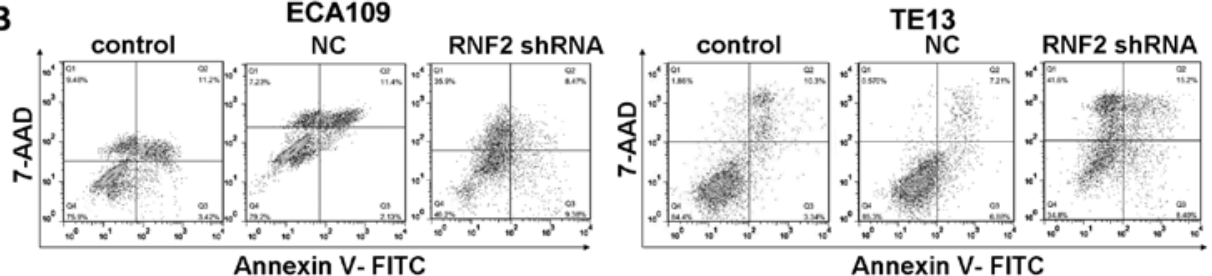

C

ECA109

TE13

四 control group

$\mathbb{D}$ NC group

白 RNF2 shRNA group
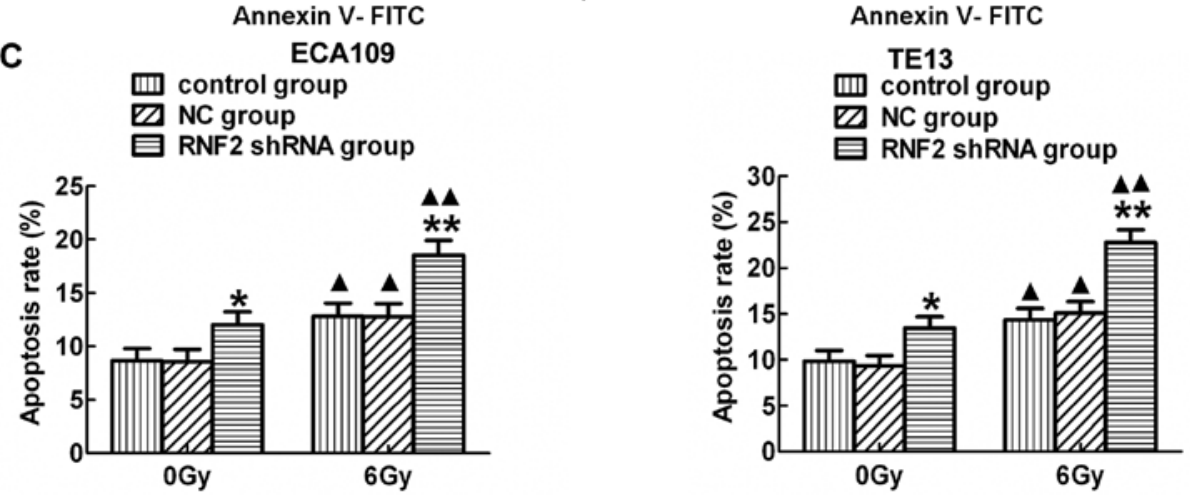

Figure 5. Apoptosis rates among different groups in ECA109 and TE13 cells in vitro. (A) The apoptosis rates in three groups were significantly different after exposure to irradiation in cells and obviously higher than their corresponding groups before IR. (B) Besides, the apoptosis rates were significantly higher in RNF2 shRNA group than those of control and NC groups after exposure to irradiation. (C) The data are shown as the means \pm standard error for each group before and after IR. ${ }^{*} \mathrm{P}<0.05,{ }^{* *} \mathrm{P}<0.01$ compared with control group and $\mathrm{NC}$ group. ${ }^{\wedge} \mathrm{P}<0.05,{ }^{\wedge} \mathrm{P}<0.01$ compared with corresponding unirradiated group.

In addition, the apoptosis rate in RNF2 shRNA group was significantly higher than the other two groups in both ECA109 and TE13 cells before (Fig. 5A) and after IR (Fig. 5B; P<0.05). Moreover, a strong increase in apoptosis was detected in both cell lines after IR compared to the corresponding irradiated groups $(\mathrm{P}<0.05)$. Furthermore, the expression of several cell survival-related proteins was evaluated by western blot analysis (Fig. 6A). Following RNF2 silencing, the expression of Bcl-2 was decreased (Fig. 6B), while the expression of Bax was increased before and after IR (Fig. 6C), and the level of these indexes was higher after IR than before IR $(\mathrm{P}<0.05)$. Thus, RNF2 has an ability to regulate the cell cycle, and induce apoptosis thus promoting radiosensitivity after IR.

\section{Discussion}

Esophageal carcinoma is one of the most frequent malignant tumors, with high morbility and mortality worldwide. For example, the incidence of esophageal carcinoma is as high as 26.3/100,000 individuals in America, which is higher than in Asia. Radiotherapy is one of the most important therapeutic stragies for esophageal carcinoma, however, the 5-year survival rate is only from 10 to $15 \%$, accompanied high recurrence rate from $\sim 60$ to $80 \%$. Although the local control rate is improved after extensive application of new techniques in radiotherapy, local failure is still the main cause of death. Moreover, the molecular mechanisms behind the development and progression of esophageal carcinoma after RT are uncertain.
RNF2, one of core components in the polycomb repressive complex 1, may play an important role in the immortalization of normal epithelial cells, early malignant transformation, the maintenance of the self-renewal of stem cells, and carcinogenesis (16-18). In addition to their role in development, RNF2 has been reported to be overexpressed in a variety of human cancers, such as various malignant solid tumors (19). In the present study, we provided additional clinicopathological evidence and a mechanistic basis for the role of RNF2 in human esophageal carcinoma progression. We found that RNF2 was overexpressed in both esophageal carcinoma tissues and cell lines compared with normal esophageal tissues and a normal esophageal epithelial cell line. Here, we further demonstrated that aberrant cytoplasm overexpression of RNF2 was positively correlated with tumor size and lymph node metastases, but negatively correlated with patient survival, underscoring the role of RNF2 in the progression of esophageal carcinoma. Indeed, this association between RNF2 upregulation and tumor size, pathological grade, and an adverse prognosis is not unprecedented, as similar findings have been reported in other tumor types (20). However, there is no statistically significant correlation between RNF2 overexpression and the age or gender of esophageal carcinoma patients. The reason may be due to the small number of cases examined in the present study, and therefore additional specimens would need to be analyzed to confirm our results.

To further confirm the significance of RNF2 overexpression in the progression of esophageal carcinoma, we designed and 
A
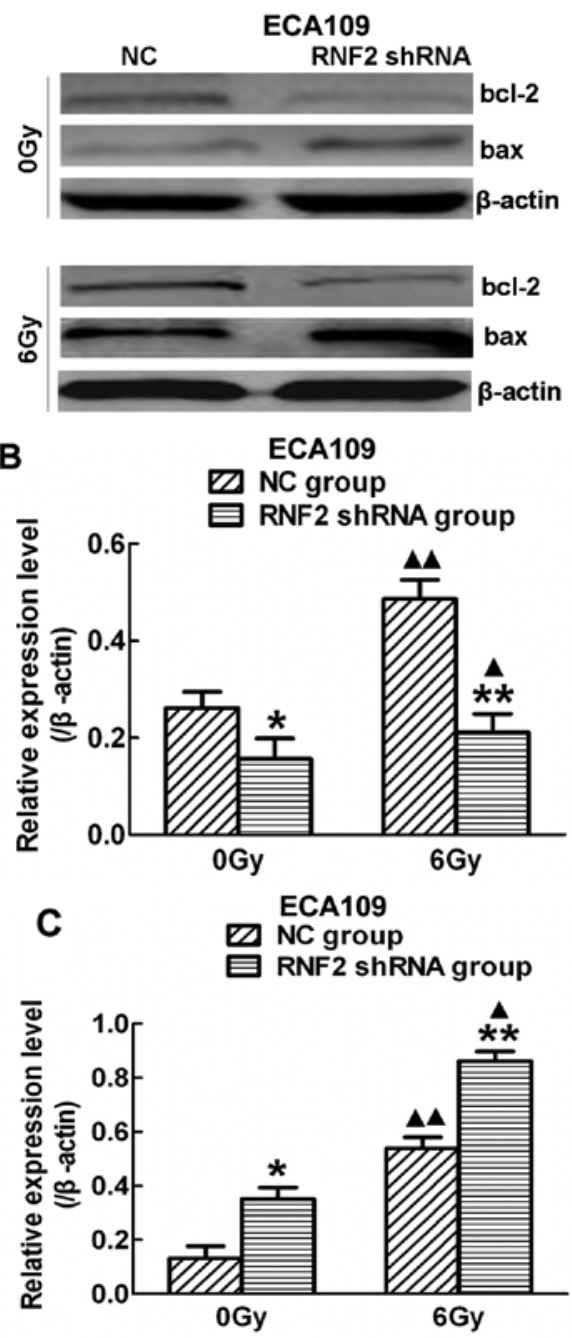
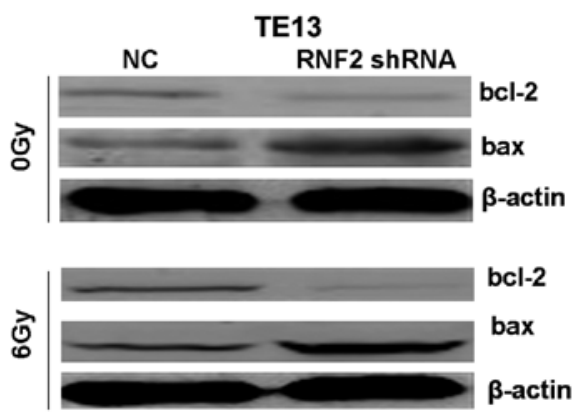

TE13

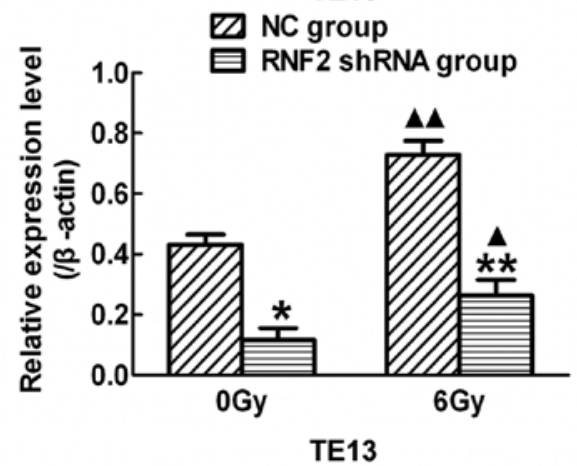

$\square$ NC group

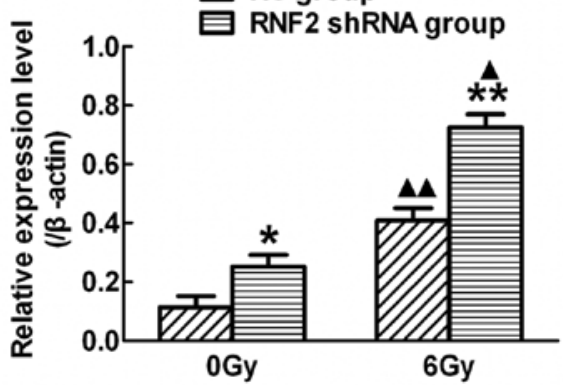

Figure 6. Protein expression associated with apoptosis among different groups in ECA109 and TE13 cells in vitro. Expression of Bcl-2 and Bax after irradiation in each group was higher than before IR (A). In addition, the downregulation of Bcl-2 (B) and upregulation of Bax (C) in ECA109 and TE13 cells was significantly observed before and after exposure to irradiation in RNF2 shRNA group. ${ }^{*} \mathrm{P}<0.05,{ }^{* *} \mathrm{P}<0.01$ compared with $\mathrm{NC}$ group. ${ }^{\wedge} \mathrm{P}<0.05,{ }^{\wedge} \mathrm{P}<0.01$ compared with corresponding unirradiated group.

constructed shRNA recombinant expression vector targeting RNF2 to downregulate its expression in both the protein and mRNA level in two esophageal carcinoma cell lines. We investigated the effect of RNF2 shRNA on the proliferation and radiosensitivity of esophageal carcinoma cells upon irradiation. RNF2 gene knockdown in ECA109 and TE13 cells significantly inhibited cell proliferation and improved radiosensitivity after the cells were treated with shRNA and irradiation at different times. Previous studies have reported that the downregulation of RNF2 by the adenovirus-mediated delivery of RNF2 shRNA reduced the proliferation, and invasion of cancer cells, and decreased the radioresistance (15). Our results were in accordance with previous studies. Notably, there was no obvious difference in cell proliferation of different groups without irradiation, manifesting that radiotherapy combined with shRNA can effectively inhibit the proliferation of tumor cells and enhance the radiosensitization.

It has been reported that RNF2 was associated with ubiquitination and phosphorylation of $\operatorname{H} 2 \mathrm{AX}(8,21)$. Similar studies identified that RNF2 possesses the E3 ligase activity for $\mathrm{H} 2 \mathrm{AX}$ monoubiquitination and interacts with $\mathrm{H} 2 \mathrm{AX}$ in a DNA damage-induced manner $(22,23)$. In accordance with previous studies, we found RNF2 regulated monoubiquitination and phosphorylation of $\mathrm{H} 2 \mathrm{AX}$ in the DNA damage response induced by ionizing radiation in a dose-dependent and time-dependent manner. In addition, the interaction between RNF2 and H2AK119ub, r-H2AX was obviously enhanced in esophageal carcinoma after exposure to IR, while there was no significant interaction without irradiation, indicating a vital role of RNF2 in DNA damage response and its potential mechanism. However, we did not assess whether RNF2 is involved in ubiquitination or phosphorylation of H2AX. Thus, we will evaluate this aspect in order to better explore its related mechanism of RNF2 in DNA damage response.

Cellular responses to DNA damage include cell cycle arrest and apoptosis. Previous studies have reported that downregulation of RNF2 caused G0/G1 arrest in Tera-1 cells (7). Our data demonstrated that inhibiting the expression of RNF2 by shRNA in ECA109 and TE13 cells significantly induced spontaneous cell apoptosis and cell cycle arrest at the G0/G1 phase after IR. However, given no ionizing radiation, there was no statistically significant difference among the 
control group, NC group and RNF2 shRNA group. We also detected the expression of several known G0/G1 cell cyclerelated proteins in different groups before and after IR. As a result, obvious decreases in the levels of cyclin D2, CDK4 and marked increases of p16 were observed after RNF2-depletion and IR. However, their levels had no significant alteration before IR. P16 is a member of CDK inhibitors which mediated negative effects on cell cycle progression through the binding of various cyclin-CDK complexes and suppression of their viability (24). Prior studies demonstrated that $\mathrm{rH} 2 \mathrm{AX}$, phosphorylation of $\mathrm{H} 2 \mathrm{AX}$ and a marker of DNA damage response, was associated with p16 and p53 $(25,26)$. DNA damage can induce the expression of p53 and p16, enhancing cell cycle arrest at G1 phase (27). In the present study, RNF2 depletion downregulated the level of cyclin D2, CDK and upregulated the expression of p16, and then altered cell cycle distribution. Interestingly, knockdown of RNF2 also decreased the expression of H2AX. As described above, the expression of RNF2 was related to ubiquitination or phosphorylation of H2AX. Therefore, these results suggest that RNF2-mediated promotion of tumor progression is related to increased cell growth via interaction with $\mathrm{H} 2 \mathrm{AX}$ to regulate the expression of some cyclins and p16, and further to regulate the cell cycle.

In the present study, our data showed that apoptosis of cells was higher in RNF2 shRNA group than control group and NC group before and after exposure to irradiation. Moreover, our results also detected the promotion effect of RNF2 shRNA on apoptosis in ECA109 and TE13 cells after treated with irradiation which was accompanied by downregulated expression of Bcl-2 and upregulation of Bax, which are the downstream targets of the nuclear factor-kappa B (NF- $\kappa \mathrm{B})$ and associated with cell apoptosis after DNA damage (28). Thus, these data demonstrated the downregulation of RNF2 shRNA enhances IR-induced apoptosis. RNF2-mediated Bcl-2 and Bax expression may serve as a novel pathway to contribute to esophageal carcinoma progression. Moreover, a recent study showed that RNF2 silencing significantly sensitized glioma cells to irradiation in vitro through increasing apoptosis (29). Therefore, our results suggest the mechanism of RNF2-mediated promotion of tumor progression may be associated with Bcl-2 family proteins to enhance cell survival.

In summary, the present study detected RNF2 expression and its clinical significance in esophageal carcinoma. RNF2 was found to be overexpressed in esophageal carcinoma cell lines and was associated with the poor prognosis of esophageal carcinoma patients. Our data reflect the important role of RNF2 in the growth of esophageal carcinoma cells by shRNA silencing of RNF2 expression. In addition, downregulation of RNF2 decreased Bcl-2 expression, enhanced Bax expression and induced IR-induced G0/G1 arrest by inhibiting RNF2 expression. To the best of our knowledge, we demonstrated the suppression of RNF2 expression by shRNA in esophageal carcinoma for the first time after treatment with irradiation, indicating that RNF2 may be an important gene for targeted therapy of human esophageal carcinoma.

\section{Acknowledgements}

The present study was supported by the National Natural Science Foundation of China (no. 81372416).

\section{References}

1. Sun Y, Liu M, Yang B, Li B and Lu J: Role of siRNA silencing of MMP-2 gene on invasion and growth of laryngeal squamous cell carcinoma. Eur Arch Otorhinolaryngol 265: 1385-1391, 2008

2. Zhao JX and Xie XL: Regulation of gene expression in laryngeal carcinama by microRNAs. Int J Pathol Clin Med 32: 222-225, 2012.

3. Nacerddine K, Beaudry JB, Ginjala V, Westerman B, Mattiroli F, Song JY, van der Poel H, Ponz OB, Pritchard C, CornelissenSteijger $\mathrm{P}$, et al: Akt-mediated phosphorylation of Bmil modulates its oncogenic potential, E3 ligase activity, and DNA damage repair activity in mouse prostate cancer. J Clin Invest 122: 1920-1932, 2012.

4. Sánchez-Beato M, Sánchez E, González-Carreró J, Morente M Díez A, Sánchez-Verde L, Martín MC, Cigudosa JC, Vidal M and Piris MA: Variability in the expression of polycomb proteins in different normal and tumoral tissues. A pilot study using tissue microarrays. Mod Pathol 19: 684-694, 2006.

5. Martínez-Romero C, Rooman I, Skoudy A, Guerra C, Molero X, González A, Iglesias M, Lobato T, Bosch A, Barbacid M, et al: The epigenetic regulators Bmil and Ring1B are differentially regulated in pancreatitis and pancreatic ductal adenocarcinoma. J Pathol 219: 205-213, 2009.

6. Bosch A, Panoutsopoulou K, Corominas JM, Gimeno R, Moreno-Bueno G, Martín-Caballero J, Morales S, Lobato T, Martínez-Romero C, Farias EF, et al: The Polycomb group protein RING1B is overexpressed in ductal breast carcinoma and is required to sustain FAK steady state levels in breast cancer epithelial cells. Oncotarget 5: 2065-2076, 2014.

7. Su WJ, Fang JS, Cheng F, Liu C, Zhou F and Zhang J: RNF2/ Ring $1 \mathrm{~b}$ negatively regulates $\mathrm{p} 53$ expression in selective cancer cell types to promote tumor development. Proc Natl Acad Sci USA 110: 1720-1725, 2013.

8. Pan MR, Peng G, Hung WC and Lin SY: Monoubiquitination of $\mathrm{H} 2 \mathrm{AX}$ protein regulates DNA damage response signaling. J Biol Chem 286: 28599-28607, 2011.

9. Wu CY, Kang HY, Yang WL, Wu J, Jeong YS, Wang J, Chan $\mathrm{CH}$, Lee SW, Zhang X, Lamothe B, et al: Critical role of monoubiquitination of histone $\mathrm{H} 2 \mathrm{AX}$ protein in histone $\mathrm{H} 2 \mathrm{AX}$ phosphorylation and DNA damage response. J Biol Chem 286: 30806-30815, 2011.

10. Hongyun S and Shuchai Z: Radiosensitization of esophageal cancer cells ECA109 by knockdown of H2AX. Thorac Cancer 4: 1759-7706, 2013

11. Song W, Li H, Tao K, Li R, Song Z, Zhao Q, Zhang F and Dou K: Expression and clinical significance of the stem cell marker CD133 in hepatocellular carcinoma. Int J Clin Pract 62: 1212-1218, 2008.

12. Song LB, Zeng MS, Liao WT, Zhang L, Mo HY, Liu WL, Shao JY, Wu QL, Li MZ, Xia YF, et al: Bmi-1 is a novel molecular marker of nasopharyngeal carcinoma progression and immortalizes primary human nasopharyngeal epithelial cells. Cancer Res 66: 6225-6232, 2006.

13. Livak KJ and Schmittgen TD: Analysis of relative gene expression data using real-time quantitative PCR and the 2(-Delta Delta C(T)) method. Methods 25: 402-408, 2001.

14. Bartek $\mathrm{J}$ and Lukas $\mathrm{J}$ : Chk1 and Chk2 kinases in checkpoint control and cancer. Cancer Cell 3: 421-429, 2003.

15. Chen J, Xu H, Zou X, Wang J, Zhu Y, Chen H, Shen B, Deng X, Zhou A, Chin YE, et al: Snail recruits Ring1B to mediate transcriptional repression and cell migration in pancreatic cancer cells. Cancer Res 74: 4353-4363, 2014.

16. Rai K, Akdemir KC, Kwong LN, Fiziev P, Wu CJ, Keung EZ, Sharma S, Samant NS, Williams M, Axelrad JB, et al: Dual roles of RNF2 in melanoma progression. Cancer Discov 5: 1314-1327, 2015.

17. van der Stoop P, Boutsma EA, Hulsman D, Noback S, Heimerikx M, Kerkhoven RM, Voncken JW, Wessels LF and van Lohuizen M: Ubiquitin E3 ligase Ring1b/Rnf2 of polycomb repressive complex 1 contributes to stable maintenance of mouse embryonic stem cells. PLoS One 3: e2235, 2008.

18. van der Velden YU, Wang L, Querol Cano L and Haramis AP: The polycomb group protein ring $1 \mathrm{~b} / \mathrm{rnf} 2$ is specifically required for craniofacial development. PLoS One 8: e73997, 2013.

19. Yamamoto Y, Abe A and Emi N: Clarifying the impact of polycomb complex component disruption in human cancers. Mol Cancer Res 12: 479-484, 2014. 
20. Chen S, Chen J, Zhan Q, Zhu Y, Chen H, Deng X, Hou Z, Shen B, Chen Y and Peng C: H2AK119Ub1 and H3K27Me3 in molecular staging for survival prediction of patients with pancreatic ductal adenocarcinoma. Oncotarget 5: 10421-10433, 2014.

21. Hasegawa K, Sin HS, Maezawa S, Broering TJ, Kartashov AV, Alavattam KG, Ichijima Y, Zhang F, Bacon WC, Greis KD, et al: SCML2 establishes the male germline epigenome through regulation of histone H2A ubiquitination. Dev Cell 32: 574-588, 2015.

22. Zaaroor-Regev D, de Bie P, Scheffner M, Noy T, Shemer R, Heled M, Stein I, Pikarsky E and Ciechanover A: Regulation of the polycomb protein Ring1B by self-ubiquitination or by E6-AP may have implications to the pathogenesis of Angelman syndrome. Proc Natl Acad Sci USA 107: 6788-6793, 2010.

23. Leung JW, Agarwal P, Canny MD, Gong F, Robison AD, Finkelstein IJ, Durocher D and Miller KM: Nucleosome acidic patch promotes RNF168- and RING1B/BMI1-dependent H2AX and $\mathrm{H} 2 \mathrm{~A}$ ubiquitination and DNA damage signaling. PLoS Genet 10: e1004178, 2014.

24. Boquoi A, Arora S, Chen T, Litwin S, Koh J and Enders GH: Reversible cell cycle inhibition and premature aging features imposed by conditional expression of p16Ink4a. Aging Cell 14: $139-147,2015$
25. Blanco D, Vicent S, Fraga MF, Fernandez-Garcia I, Freire J, Lujambio A, Esteller M, Ortiz-de-Solorzano C, Pio R, Lecanda F, et al: Molecular analysis of a multistep lung cancer model induced by chronic inflammation reveals epigenetic regulation of p16 and activation of the DNA damage response pathway. Neoplasia 9: 840-852, 2007

26. Wen W, Peng C, Kim MO, Ho Jeong C, Zhu F, Yao K, Zykova T, Ma W, Carper A, Langfald A, et al: Knockdown of RNF2 induces apoptosis by regulating MDM2 and p53 stability. Oncogene 33: 421-428, 2014

27. Shapiro GI, Edwards CD, Ewen ME and Rollins BJ: p16 $6^{\mathrm{INK} 4 \mathrm{~A}}$ participates in a G1 arrest checkpoint in response to DNA damage. Mol Cell Biol 18: 378-387, 1998.

28. Loriot Y, Mordant P, Dugue D, Geneste O, Gombos A Opolon P, Guegan J, Perfettini JL, Pierre A, Berthier LK, et al: Radiosensitization by a novel Bcl-2 and Bcl-XL inhibitor S44563 in small-cell lung cancer. Cell Death Dis 5: e1423, 2014.

29. Zhou C, Yang F, Xi W, Wei M, Zheng G, Wang W, Yang A, Zhang J and Wen W: Effect of RNF2 knockdown on apoptosis and radiosensitivity in glioma U87 cells. Xi Bao Yu Fen Zi Mian Yi Xue Za Zhi 30: 471-475, 2014 (In Chinese). 